\title{
Patient-Centered Guidelines for Geriatric Diabetes Care: Potential Missed Opportunities to Avoid Harm
}

\author{
Ellen M. McCreedy, PhD, Robert L. Kane, MD, † Sarah E. Gollust, PhD, \\ Nathan D. Shippee, PhD, and Kirby D. Clark, MD
}

Background: Clinicians strive to deliver individualized, patient-centered care. However, these intentions are understudied. This research explores how patient characteristics associated with an high riskto-benefit ratio with hypoglycemia medications affect decision making by primary care clinicians.

Methods: Using a vignette-based survey, we queried primary care clinicians on their intended management of geriatric patients with diabetes. The patients' ages, disease durations, and comorbidities were systematically varied. Clinicians indicated whether they would intensify glycemic control by adding a second-line hypoglycemia medication.

Results: A convenience sample of 336 primary care clinicians completed the survey. Despite the recommendations for $\mathrm{HbA}_{1 \mathrm{c}}$ targets $<8 \%$ for more complex patients, an 80-year-old woman with an $\mathrm{HbA}_{1 \mathrm{c}}$ of $7.5 \%$, longstanding diabetes, coronary disease, and cognitive impairment and with instrumental activity of daily living dependencies, had a predicted probability of treatment intensification of $35 \%$. Internists were $11 \%$ and nurse practitioners were $14 \%$ more likely to intensify treatment than family physicians $(P<.01)$. These provider differences remained significant after controlling for geographic differences in treatment intensification. Providers in Florida were more likely to intensify treatment $(P<.01)$.

Conclusions: Primary care clinicians often chose to intensify glycemic control despite individual patient factors that warrant higher glycemic targets based on existing guidelines. This research identifies possible missed opportunities for patient-centered goal setting and raises questions about the influence of training and practice environment on clinical decision making. (J Am Board Fam Med 2018;31:192-200.)

Keywords: Blood Glucose, Clinical Decision-Making, Diabetes Mellitus, Geriatric Health Services, Hyperglycemia, Hypoglycemic Agents, Patient-Centered Care, Primary Health Care

Older adults with diabetes are at greater risk for adverse consequences of the disease, notably hypoglycemia, with tight glycemic control. ${ }^{1-3}$ This is particularly true for older adults with long-standing diabetes, coexisting cardiovascular disease, or cognitive impairment. This iatrogenic risk also increases with age. The rate of hospitalization for

This article was externally peer reviewed.

Submitted 30 March 2017; revised 19 October 2017; accepted 29 October 2017.

From the Division of Health Policy and Management, University of Minnesota School of Public Health, Minneapolis (EMM, SEG, NDS); University of Minnesota School of Public Health, Minneapolis (RLK); and the Department of Family Medicine and Community Health, University of Minnesota Medical School, Minneapolis (KDC).

†Died March 6, 2017. hypoglycemia in diabetic patients aged $\geq 75$ years is twice that of those aged 65 to 74 , and rates of hospitalization for hypoglycemia now exceed those for hyperglycemia among the Medicare population. $^{4}$

To avoid this harm, the American Diabetes Association $(\mathrm{ADA})^{5,6}$ and the American Geriatric Society $^{7,8}$ recommend tailoring glycemic targets based on

Funding: EMM is supported by an Agency for Healthcare Research and Quality National Research Service Award (4T32 HS000011-30).

Conflict of interest: none declared.

Corresponding author: Ellen M. McCreedy, PhD, Center for Gerontology and Healthcare Research, Brown University, School of Public Health, 121 South Main Street, Suite 6, Providence, RI 02903 (E-mail: ellen_mccreedy@brown. edu). 
a patient's life expectancy, number and severity of comorbid chronic diseases, and cognitive and physical functioning. According to the ADA guidelines for older adults ${ }^{6}$, glycohemoglobin $\left(\mathrm{HbA}_{1 \mathrm{c}}\right)$ targets $<7.5 \%$ are appropriate for older adults with few comorbid conditions and intact cognitive and physical functioning (healthy); targets $<8 \%$ are appropriate for older adults with comorbid chronic diseases, impaired instrumental activities of daily living (IADLs), or mild to moderate cognitive impairment (complex/intermediate); and targets $<8.5 \%$ are appropriate for patients with endstage illness receiving long-term care, with moderate to severe cognitive impairment, or with impaired activities of daily living (very complex/ poor health). The American Geriatric Society endorses this 3-tiered approach to glycemic management with a lower bound of $7 \%$ for all older adults and an upper bound of $9 \%$ for those with poor health and limited life expectancy. ${ }^{8}$

Despite all the effort that has gone into creating these consensus statements, a paucity of the literature examines how clinicians respond to these recommendations in practice when tailoring treatment for individual patients with diabetes. In this study we focus on community-dwelling older adults with diabetes who fit into the healthy and intermediate categories of clinical complexity and, per existing guidelines, should have $\mathrm{HbA}_{1 \mathrm{c}}$ targets $<7.5 \%$ (healthy) or $<8 \%$ (complex/intermediate). We presented common patient scenarios to primary care clinicians, who most often manage older adults with diabetes, in order to investigate the effect of certain patient characteristics on their decision making. We specifically measured whether clinicians would chose to intensify treatment (defined as adding a second agent) and how this intensification varied by patient characteristics. We hypothesized that clinicians would treat more aggressively younger patients without cognitive impairment or a history of heart disease.

\section{Methods}

This study used a vignette survey of primary care clinicians, including internal medicine (IM) physicians, family medicine (FM) physicians, and nurse practitioners (NPs). A vignette was a 1-paragraph description of a common patient scenario. We systematically varied the patient characteristics to better understand whether clinicians individualize care and what patient factors drive these treatment decisions. Respondents were specifically asked whether they would add a second-line diabetes medication (intensify medication therapy) for a patient who had already been treated for 6 months with first-line metformin therapy.

\section{Data and the Sample}

A convenience sample was obtained primarily through the use of state licensure lists from Minnesota and Florida. We also had participants from 3 Agency for Health Care Research and Quality practice-based research networks (PBRNs) and a small state professional association meeting. To be eligible, physicians and NPs had to be actively practicing primary care medicine at least $75 \%$ of the time.

For the PBRNs, participants were contacted by the network director using a standardized e-mail invitation with an embedded link to complete the online survey. E-mail addresses of PBRN members were not released to investigators. For the clinician e-mails obtained through licensure lists, the study primary investigator (EMM) e-mailed clinicians directly using the same standardized e-mail invitation used by the PBRNs. All responses were collected anonymously using Qualtrics software. A small number of study participants completed the study in person while attending a state professional association meeting. This study was exempted from full review by the University of Minnesota Institutional Review Board Human Subjects Committee (study no. 1305E33481).

\section{Vignette Design}

The patient factors randomly varied in the vignettes were $\mathrm{HbA}_{1 \mathrm{c}}$ level, age, disease duration, presence of cognitive impairment with IADL dependencies, and history of coronary artery disease with previous coronary artery bypass graft. Each of the 4 patient characteristics were presented at 2 $\mathrm{HbA}_{1 \mathrm{c}}$ levels (Table 1 ), yielding a total of 16 possible vignette combinations. All vignettes depicted a hypothetical patient of the same sex, weight, kidney function, and ability to pay for medications. In addition, every patient had hypertension, mild neuropathic symptoms, no comorbid depression, and no activity of daily living dependencies. Each respondent viewed 4 randomly selected vignettes. 
Table 1. Description of Patient Characteristics Systematically Varied in Factorial Vignettes

\begin{tabular}{|c|c|c|}
\hline Vignette Factor & Level 1 (Healthy)* & Level 2 (Complex/Intermediate Health)* \\
\hline $\mathrm{HbA}_{1 \mathrm{c}}$ & $7.5 \%$ & $8.5 \%$ \\
\hline \multirow[t]{2}{*}{ Age/disease duration } & 65 years old & 80 years old \\
\hline & Type 2 diabetes for 5 years & Type 2 diabetes for 15 years \\
\hline \multirow{3}{*}{$\begin{array}{l}\text { Presence of cognitive } \\
\text { impairment }\end{array}$} & No information & Some recent memory loss on formal testing \\
\hline & & $\begin{array}{l}\text { She lives independently but depends on her eldest daughter } \\
\text { to keep her medical appointments and pay her bills }\end{array}$ \\
\hline & & She stopped driving, in part because she occasionally got lost \\
\hline History of heart disease & $\begin{array}{l}\text { No history of cardiovascular } \\
\text { disease }\end{array}$ & $\begin{array}{l}\text { Coronary artery disease, for which she underwent a coronary } \\
\text { artery bypass graft } 5 \text { years ago }\end{array}$ \\
\hline
\end{tabular}

*The American Diabetes Association recommends glycated hemoglobin $\left(\mathrm{HbA}_{1 \mathrm{c}}\right)$ targets $<7.5 \%$ for older adults with few comorbid conditions and intact cognitive and physical functioning (healthy), and targets $<8 \%$ for older adults with comorbid chronic diseases, impaired instrumental activities of daily living, or mild to moderate cognitive impairment (complex/intermediate).

Therefore, every clinician did not receive the same survey. A sample vignette and the response set are provided in the Appendix.

\section{Measures}

Treatment intensification was defined as adding any 1 of 5 classes of approved second-line medication therapies. A dichotomous variable was created to indicate intensification of medication therapy. Any choice to add another medication was categorized as treatment intensification.

In addition to the vignette characteristics, we investigated the effects of several clinician characteristics on the decision to intensify treatment. Clinician training was defined using an item that asked respondents to self-identify as "physician, family medicine," "physician, internal medicine," "nurse practitioner," or "other." Clinicians were not specifically asked about specializations. Other clinician and practice characteristics were investigated: year in which the respondent finished professional education, average duration of a routine visit (minutes), and percentage of practice that is Medicare $(<25 \%$, $25-75 \%,>75 \%)$.

\section{Analyses}

We used bivariate analysis and multivariate regression to study the effect of vignette characteristics on the decision to intensify treatment. Because clinicians viewed $>1$ vignette, we used random effects probit, a regression model that accounts for correlations between responses from the same clinician, or clinician cluster effects. Vignette and clinician characteristics were entered into the model as fixed effects, with a random intercept for each clinician. The random effects model assumed that variation across respondents is not correlated with the independent variables included in the model (vignette factors). The Hausman test confirmed that this assumption held for the current analysis and that random effects was an appropriate model $(P=.30$, fail to reject null hypothesis that variation across respondents is correlated with predictors). We also were able to estimate the intraclass correlation, or the amount of total variation attributable to idiosyncratic clinician effects. All analyses were conducted using Stata software version 14.

\section{Results}

A total of 366 clinicians comprised the analytic sample. We excluded 30 surveys (8\% of respondents) from the analytic sample because their selfreported specialty was "other" or not provided ( $\mathrm{n}=$ $11)$, geriatric or palliative care $(n=9)$, or endocrinology or nephrology $(n=10)$. Although complete denominator information was not available, we estimated the response rates to be around $8 \%$ to $10 \%$ for respondents identified using licensure lists, $20 \%$ to $25 \%$ for those in the PBRNs, and $>80 \%$ for the participants attending a local professional conference. Data were collected between August and December 2015.

Respondent characteristics for the 73 IM physicians, 108 FM physicians, and 155 NPs are provided in Table 2 . Respondents completed their professional education (medical school for physicians) between 1955 and 2015 (median, 1996). IM physicians had, on average, 10 more years since 
Table 2. Characteristics of Primary Care Clinicians Completing Survey

\begin{tabular}{|c|c|c|c|c|}
\hline & $\begin{array}{l}\text { Total Sample } \\
(\mathrm{N}=336)\end{array}$ & $\begin{array}{c}\text { Family Medicine } \\
\text { Physicians }(\mathrm{n}=108)\end{array}$ & $\begin{array}{l}\text { Internal Medicine } \\
\text { Physicians }(\mathrm{n}=73)\end{array}$ & $\begin{array}{l}\text { Nurse Practitioners } \\
\quad(\mathrm{n}=155)\end{array}$ \\
\hline $\begin{array}{l}\text { Year professional education } \\
\text { completed, median (range) }\end{array}$ & $1996(1955-2015)$ & $1991(1968-2015)$ & $1986(1955-2011)$ & $2003(1978-2015)$ \\
\hline $\begin{array}{l}\text { Duration of routine visit (minutes), } \\
\text { mean (range) }\end{array}$ & $23(5-90)$ & $21(7-45)$ & $22(5-90)$ & $24(5-60)$ \\
\hline \multicolumn{5}{|l|}{$\begin{array}{l}\text { Medicare patients among total } \\
\text { practice }\end{array}$} \\
\hline$<25$ & 28 & 39 & 16 & 25 \\
\hline $25-75$ & 52 & 50 & 64 & 48 \\
\hline$>75$ & 20 & 11 & 19 & 26 \\
\hline \multicolumn{5}{|l|}{ State where respondents practiced } \\
\hline Florida & 52 & 22 & 49 & 73 \\
\hline Minnesota & 25 & 50 & 40 & 1 \\
\hline Other & 23 & 28 & 11 & 26 \\
\hline $\begin{array}{l}\text { Patients sampled from licensure } \\
\text { lists }\end{array}$ & 76 & 72 & 89 & 74 \\
\hline
\end{tabular}

Data are percentages unless otherwise indicated.

finishing their education (median, 1986). NPs had fewer years since completing their professional education (median, 2003). Clinicians reported a mean duration of a routine visit at 23 minutes (range, 5-90 minutes). The mean duration of a routine visit was similar across clinician types. When asked to estimate the percentage of their practice comprising Medicare patients, $28 \%$ of sample reported $<25 \%$ of their practice was Medicare patients, $20 \%$ reported $>75 \%$ of their practice is Medicare, and most respondents (52\%) had practices with between $25 \%$ and $75 \%$ Medicare patients. NPs were the most likely to report having $>75 \%$ of their patient population enrolled in Medicare, fol- lowed by IM and FM physicians. Of the sample, $52 \%$ practiced in Florida, 25\% practiced in Minnesota, and $23 \%$ practiced in other states (predominately Wisconsin and Colorado). FM physicians were mostly likely to practice in Minnesota. NPs were most likely to practice in Florida. Most of the sample $(76 \%)$ was obtained using licensure lists from Minnesota and Florida.

\section{Effect of Patient Characteristics on the Decision to Intensify Treatment}

Figure 1 presents unadjusted rates of treatment intensification by vignette characteristics at the 2 $\mathrm{HbA}_{1 \mathrm{c}}$ levels considered in this vignette study

Figure 1. Unadjusted rates of treatment intensification by vignette characteristics at 2 glycohemoglobin levels. $* P<.05 ; * * P<.01$. CABG, coronary artery bypass graft; $\mathrm{HbA}_{1 \mathrm{c}}$, glycohemoglobin; IADL, instrumental activities of daily living.

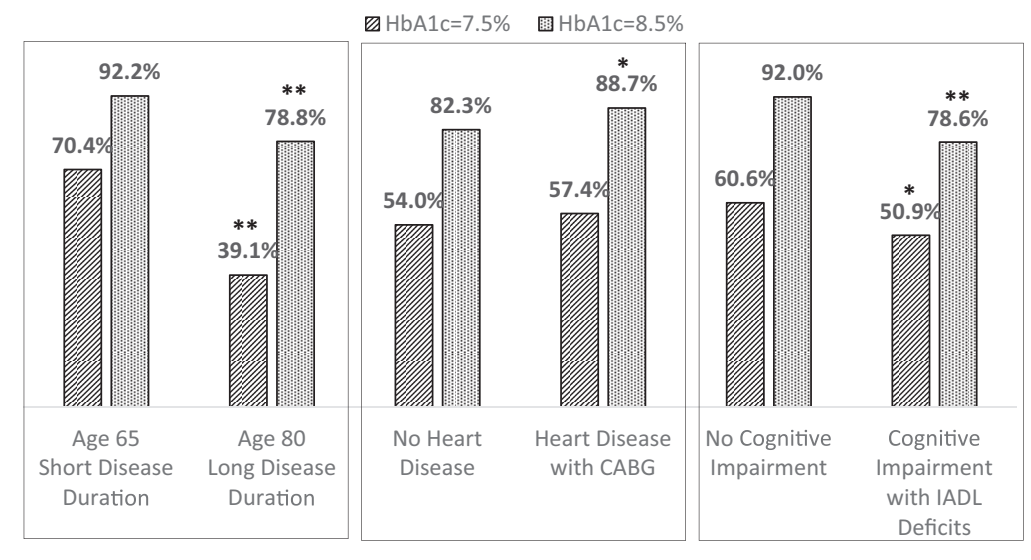




\begin{tabular}{|c|c|c|c|}
\hline & $\begin{array}{l}\text { Model 1: Patient } \\
\text { Characteristics }\end{array}$ & $\begin{array}{l}\text { Model 2: Patient and } \\
\text { Clinician Characteristics }\end{array}$ & $\begin{array}{l}\text { Model 3: Patient, Clinician, } \\
\text { and State Characteristics }\end{array}$ \\
\hline \multicolumn{4}{|l|}{ Patient characteristics } \\
\hline $8.5 \% \mathrm{HbA}_{1 \mathrm{c}}$ & $31.7^{*}(2.1)$ & $31.7^{*}(2.1)$ & $31.6^{*}(2.1)$ \\
\hline 80 years old & $-20.8^{*}(2.0)$ & $-20.9^{*}(2.0)$ & $-20.9^{*}(1.9)$ \\
\hline Heart disease & $3.0(1.9)$ & $3.0(1.9)$ & $3.0(1.9)$ \\
\hline Cognitive impairment & $-10.6^{*}(1.9)$ & $-10.6^{*}(1.9)$ & $-10.6^{*}(1.9)$ \\
\hline \multicolumn{4}{|l|}{ Clinician characteristics } \\
\hline \multicolumn{4}{|l|}{ Clinician type (reference $=$ family medicine $)$} \\
\hline Internal medicine & & $11.1^{*}(3.6)$ & $8.1^{\dagger}(3.7)$ \\
\hline Nurse practitioner & & $13.8^{*}(3.5)$ & $7.5^{\dagger}(3.8)$ \\
\hline Longer than average visit ( $>20$ minutes) & & $-0.8(3.3)$ & $1.1(3.3)$ \\
\hline $\begin{array}{l}\text { Majority }(>75 \%) \text { of practice comprises } \\
\text { Medicare patients }\end{array}$ & & $-1.0(3.8)$ & $-3.4(3.8)$ \\
\hline $\begin{array}{l}\text { Recently completed education (within } 5 \\
\text { years) }\end{array}$ & & $6.0(3.3)$ & $6.3^{\dagger}(3.2)$ \\
\hline Practice in Florida & & & $13.7^{*}(3.2)$ \\
\hline Model intraclass correlation & 0.63 & 0.60 & 0.59 \\
\hline
\end{tabular}

Data are percentage points (standard error).

${ }^{\dagger} P<.05 ;{ }^{*} P<.01$.

$\mathrm{HbA}_{1 \mathrm{c}}$, glycohemoglobin.

(7.5\% and $8.5 \%)$. An 80-year-old with long-standing diabetes was significantly more likely to have her treatment intensified than a 65 -year-old with a short diabetes duration at both $\mathrm{HbA}_{1 \mathrm{c}}$ levels $(P<$ .01). At an $\mathrm{HbA}_{1 \mathrm{c}}$ of $7.5 \%$, the 80 -year-old had her treatment intensified $39 \%$ of the time compared with $70 \%$ of the time for the 65 -year-old. Hypothetical patients with cognitive impairment that affected IADLs were also significantly less likely to have their treatment intensified at both $\mathrm{HbA}_{1 \mathrm{c}}$ levels compared with hypothetical patients without cognitive impairment. In vignettes, at an $\mathrm{HbA}_{1 \mathrm{c}}$ of $7.5 \%$, the patients with cognitive impairment had their treatment intensified $51 \%$ of the time compared with $61 \%$ of the time for patients without cognitive impairment $(P<.05)$. Having a history of heart disease with previous coronary artery bypass graft did not affect the decision to intensify treatment at an $\mathrm{HbA}_{1 \mathrm{c}}$ of $7.5 \%$. At an $\mathrm{HbA}_{1 \mathrm{c}}$ of $8.5 \%$, patients with a history of heart disease were more likely to have their treatment intensified than those without a history of heart disease in the vignettes ( $89 \%$ vs $82 \%$, respectively; $P<.05$ ).

The effects of patient characteristics in the vignette on the decision to intensify treatment were similar in the adjusted models. Using random effects probit regression (Table 3, model 1), we found that having a higher $\mathrm{HbA}_{1} \mathrm{c}(8.5 \%$ vs $7.5 \%)$ increased the probability of treatment intensifica- tion by 32 percentage points. Being 80 years old decreased the probability of treatment intensification by 21 percentage points compared with being 65 years old. Having cognitive impairment decreased the probability of treatment intensification by 11 percentage points. Coronary artery disease was not significantly associated with the probability of intensification in the full model $(P=.11)$.

\section{Effect of Clinician Characteristics on the Decision to Intensify Treatment}

Most clinician characteristics we specifically measured in the survey were not related to the decision to intensify treatment (Table 3, model 2). Having a longer than average visit duration, a predominately Medicare patient population, or recent completion of professional education (within the past 5 years) did not significantly affect the decision to intensify treatment. However, we did observe differences in intensification by clinician type. FM physicians were significantly less likely than IM physicians or NPs to intensify medication therapy in geriatric patients. NPs were 14 percentage points more likely to intensify therapy than FM physicians; IM physicians were 11 percentage points more likely to intensify therapy than FM physicians $(P<.01)$.

Some of this variation in intensification by clinician type may be better explained by geographic differences in practice patterns (Table 3 , model 3). 
Figure 2. Predicted probability of treatment intensification for the healthiest and most complex cases presented in the vignettes, overall and at 2 glycohemoglobin levels. The graph shows the predicted probability of treatment intensification for a 65 -year-old with short disease duration, no cognitive impairment, and no heart disease (healthiest vignette patient) compared with that for an 80-year-old with long-standing diabetes, cognitive impairment with impaired instrumental activities of daily living, and heart disease with previous bypass graft (most complex vignette). Marginal effects were estimated holding physician-level factors (longer than average visit length, $\geq 75 \%$ of practice comprising Medicare patients, completed education in the past 5 years, clinician type, and state where the physician practices). $\mathrm{HbA}_{1 \mathrm{c}}$, glycohemoglobin.

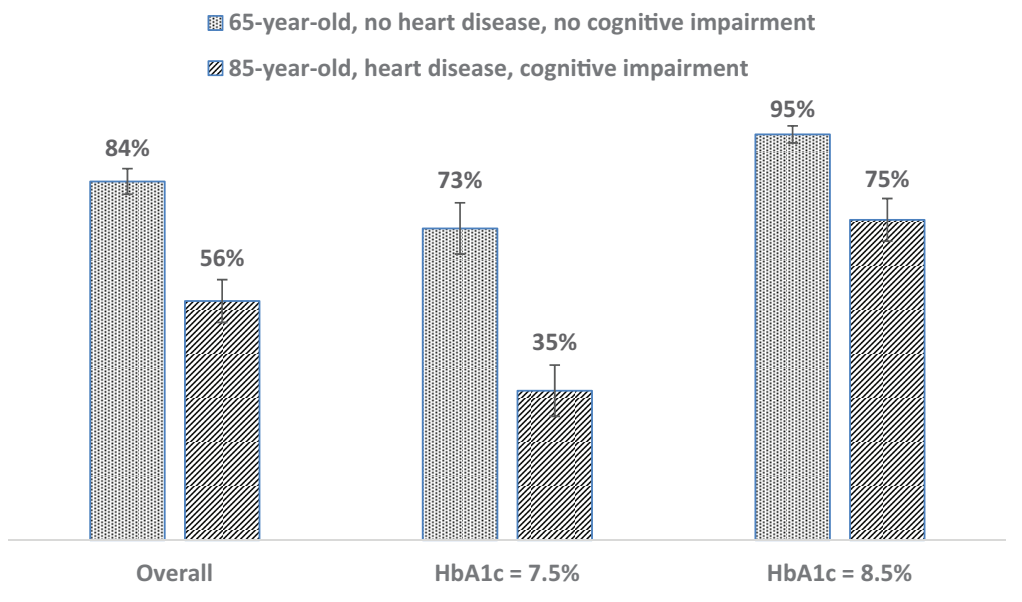

Over half of respondents to this survey and almost $75 \%$ of the NPs in the study practice in Florida. Practicing in Florida, compared with practicing in Minnesota or another state, increased the probability of treatment intensification by 14 percentage points $(P<.01)$. After accounting for geographic differences in practice patterns, NPs were 7 percentage points more likely to intensify therapy than FM physicians; IM physicians were 8 percentage points more likely to intensify therapy than FM physicians $(P<.05)$. Adding the source of the survey population (licensure vs PBRN or conference) was not significant once Florida was added to the model (results not shown). The interclass correlation reveals $59 \%$ of the variation $(95 \%$ confidence interval $[\mathrm{CI}], 49-68 \%)$ in the decision to intensify medication therapy was due to unmeasured clinician characteristics.

\section{Treatment Intensification for the Healthiest and Most Complex Hypothetical Patients}

Figure 2 shows the predicted probability of treatment intensification for the healthiest and most complex hypothetical patients in the study at 2 $\mathrm{HbA}_{1 \mathrm{c}}$ levels. A 65-year-old woman with a short diabetes duration and no heart disease or cognitive impairment had a mean predicted probability of treatment intensification of $73 \%(95 \%$ CI, $67-$ $78 \%$ ) at an $\mathrm{HbA}_{1 \mathrm{c}}$ of $7.5 \%$, and probability of $95 \%$ (95\% CI, 93-97\%) at an $\mathrm{HbA}_{1 \mathrm{c}}$ of $8.5 \%$. An 80 year-old woman with long-standing diabetes, coronary artery disease, and cognitive impairment with associated IADL impairment had a mean predicted probability of treatment intensification of $35 \%\left(95 \%\right.$ CI, 29-41\%) at an $\mathrm{HbA}_{1 \mathrm{c}}$ of $7.5 \%$ and of $75 \%(95 \%$ CI, $70-80 \%)$ at an $\mathrm{HbA}_{1 \mathrm{c}}$ of $8.5 \%$.

\section{Discussion}

The ADA guidelines for older adults ${ }^{6}$ recommend $\mathrm{HbA}_{1 \mathrm{c}}$ targets $<7.5 \%$ for older adults with few comorbid conditions and intact cognitive and physical functioning, and targets $<8 \%$ for older adults with comorbid chronic diseases, impaired IADLs, or mild to moderate cognitive impairment. In this vignette-based study, we observed appropriately high rates of treatment intensification for relatively younger patients with few comorbid conditions and intact physical and cognitive function. For otherwise healthy older adults, the mean predicted probability of treatment intensification was $73 \%$ (95\% CI, $67-78 \%$ ) at an $\mathrm{HbA}_{1 \mathrm{c}}$ of $7.5 \%$ and was $95 \%$ (95\% CI, 93-97\%) at an $\mathrm{HbA}_{1 \mathrm{c}}$ of 8.5 . However, we also detected potential missed opportunities to provide guideline-consistent care for older patients 
with comorbid cognitive impairment. An 80-yearold woman with long-standing diabetes, coronary artery disease, and cognitive impairment with associated IADL impairment had a mean predicted probability of treatment intensification of $35 \%$ (95\% CI, 29-41\%) at an $\mathrm{HbA}_{1 \mathrm{c}}$ of $7.5 \%$, despite the fact that the guidelines suggest an appropriate $\mathrm{HbA}_{1 \mathrm{c}}$ target $<8 \%$.

Contrary to expectations, preexisting cardiac complications did not decrease the likelihood that clinicians would intensify treatment in this study. Post hoc analyses of the Action to Control Cardiovascular Risk in Diabetes (ACCORD) trial and the Veteran's Affairs Diabetes Trial (VADT) suggest that tight glycemic control may confer additional risk of death for people with preexisting cardiovascular risk with long-standing diabetes. ${ }^{9,10}$ More research is needed to understand why the presence of coexisting coronary artery disease, which is specifically mentioned in existing guidelines, did not affect clinician behavior in the current study.

Our findings also hint at differences in treatment intensification by clinician type and/or by state. Overall, FM physicians were about 8 percentage points less likely than IM physicians and NPs to intensify glycemic medications. This is after controlling for a large, state-level difference in intensification between Florida and other states involved in the study (mainly Minnesota and Wisconsin). As the geriatric population continues to grow and the primary care workforce shortage deepens, the need increases for evaluation of practice patterns and patient outcomes associated with clinician type. ${ }^{11}$ Given the dramatic increase in the number of Medicare beneficiaries treated by $\mathrm{NPs}^{12}$, and given that Florida is second only to California in the number of Medicare beneficiaries, additional research is warranted to disentangle training and state effects. If clinician-type differences are replicated, policy and workforce deployment strategies may look to family medicine training programs to identify and leverage factors that promote individualized care for older adults with multiple chronic conditions.

Given the convenience nature of the sample and the low response rates, we have to be careful when interpreting and generalizing findings. In particular, we need to consider the effects of nonresponse error and coverage bias. Nonresponse error occurs when people who respond to the survey are different from those who do not respond. Clinicians who provide accurate e-mail addresses during licensure are likely different from those who do not, and clinicians who respond to unsolicited e-mails to complete surveys without a financial incentive are different from those who do not. We suspect that clinicians attending a regional conference, participating in PBRNs, or responding to an unsolicited request for help with a survey about diabetes care may be more familiar with the existing patientcentered guidelines than other clinicians. If this is the case, our estimates of potential overtreatment, or missed opportunities to follow existing recommendations for older adults, may be conservative. We also have some coverage bias. With the licensure lists, we started out with e-mails for approximately $60 \%$ of licensed primary care clinicians in Florida and Minnesota. However, 5\% to $10 \%$ of these E-mails were not active, and we were unable to estimate the percentage of remaining e-mails that were actually monitored (vs "junk e-mails"). Therefore, caution should be used when generalizing these findings to the population of all licensed primary care clinicians in those states or to all clinicians of a certain discipline.

However, with those generalizability caveats, vignette studies have been shown to be good predictors of how clinicians will behave in clinical settings. ${ }^{13}$ By systematically varying factors in existing guidelines, factorial vignette surveys are a costeffective way to broadly understand practice patterns and compliance with quality initiatives. Our estimates of potential missed opportunities are closely aligned with recent survey results revealing that one third of primary care clinicians thought it would be difficult to follow the Choosing Wisely $\mathrm{HbA}_{1 \mathrm{c}}$ recommendation for older adults, which asks clinicians to "Avoid using medications other than metformin to achieve hemoglobin $\mathrm{A}_{1 \mathrm{c}}<7.5 \%$ in most older adults." ${ }^{14}$ As part of the same study, clinicians reported existing pay-for-performance (P4P) initiatives tied to lower $\mathrm{HbA}_{1 \mathrm{c}}$ levels and fear of potential litigation as reasons they may not reduce medication burden as a person develops additional comorbid complications that limit life expectancy. ${ }^{14} \mathrm{P} 4 \mathrm{P}$ or pay-for-quality incentives rewarding intermediate outcomes $\left(\mathrm{HbA}_{1 \mathrm{c}}\right.$ levels) below a certain threshold (eg, <8\%) are widespread. ${ }^{15,16}$ Policy options to address overtreatment include incentives to appropriately deintensify treatment ${ }^{17}$ or to decrease rates of hypoglycemia. ${ }^{18}$ It is important that we align incentives to provide appropriate care throughout 
the implementation and evaluation of the MeritBased Incentive Payment System. ${ }^{19}$

Finally, our study shows that $59 \%$ of the variation in the decision to intensify medication therapy was not related to the factors mentioned in the existing patient-centered guidelines (age, disease duration, cognitive impairment, and cardiac complications) or to the clinician factors we measured. We are left to speculate as to the other factors affecting primary care clinicians' decisions to intensify glycemic medication therapy. In addition to P4P incentives, these "other factors" likely include the influence of training/mentorship ${ }^{20}$, environmental or regional variation in medication use (we found some evidence of state variation in the current study) ${ }^{21}$, influence of drug companies on individuals $^{22,23}$, or habitual prescribing behavior. ${ }^{24}$ These factors are likely to affect the degree of success we have implementing current (or future) guidelines and therefore deserve careful consideration and more research.

Our findings add to an important and growing body of evidence of missed opportunities to consider comorbid conditions indicating higher glycemic targets in order to avoid known harms. ${ }^{1,4,14,25-28}$ In addition, factorial vignettes may serve as a tool for identifying and providing feedback to individual clinicians and health care systems regarding the (under)value placed on individualized, patientcentered care. Future research should further investigate the process and influences on clinician decision making regarding individualizing glucose targets for high-risk geriatric patients, including the influence of training and practice environment. The policy implications are substantial, including the construction of performance incentives, quality reporting, and primary care workforce recommendations.

To see this article online, please go to: http://jabfm.org/content/ 31/2/192.full.

\section{References}

1. Punthakee Z, Miller ME, Launer LJ, et al. Poor cognitive function and risk of severe hypoglycemia in type 2 diabetes: post hoc epidemiologic analysis of the ACCORD trial. Diabetes Care 2012;35: 787-93.

2. Huang ES, Laiteerapong N, Liu JY, John PM, Moffet HH, Karter AJ. Rates of complications and mortality in older patients with diabetes mellitus: the diabetes and aging study. JAMA Intern Med 2014; 174:251-8.
3. Frier BM, Schernthaner G, Heller SR. Hypoglycemia and cardiovascular risks. Diabetes Care 2011; 34(Suppl 2):S132-7.

4. Lipska KJ, Ross JS, Wang Y, et al. National trends in US hospital admissions for hyperglycemia and hypoglycemia among Medicare beneficiaries, 1999 to 2011. JAMA Intern Med 2014;174:1116-24.

5. American Diabetes Association. 6. Glycemic targets [published correction appears in Diabetes Care 2017: (Suppl 1):S48-56]. Diabetes Care 2017;40(Suppl 1): S48-56.

6. American Diabetes Association. 11. Older adults. Diabetes Care 2017;40(Suppl 1):S99-104.

7. American Geriatrics Society Expert Panel on Care of Older Adults with Diabetes Mellitus; Moreno G, Mangione CM, Kimbro L, Vaisberg E. Guidelines abstracted from the American Geriatrics Society Guidelines for Improving the Care of Older Adults with Diabetes Mellitus: 2013 update. J Am Geriatr Soc 2013;61:2020-6.

8. Huang ES, Davis AM. Glycemic control in older adults with diabetes mellitus. JAMA 2015;314:1509-10.

9. Skyler JS, Bergenstal R, Bonow RO, et al; American Diabetes Association; American College of Cardiology Foundation; American Heart Association. Intensive glycemic control and the prevention of cardiovascular events: implications of the ACCORD. ADVANCE, and VA diabetes trials: a position statement of the American Diabetes Association and a scientific statement of the American College of Cardiology Foundation and the American Heart Association. Diabetes Care 2009;32:187-92.

10. Action to Control Cardiovascular Risk in Diabetes Study Group; Gerstein HC, Miller ME, Byington $\mathrm{RP}$, et al. Effects of intensive glucose lowering in type 2 diabetes. N Engl J Med 2008;358:2545-59.

11. Kuo YF, Goodwin JS, Chen NW, Lwin KK, Baillargeon J, Raji MA. Diabetes mellitus care provided by nurse practitioners vs primary care physicians. J Am Geriatr Soc 2015;63:1980-8.

12. Kuo YF, Loresto FL Jr, Rounds LR, Goodwin JS. States with the least restrictive regulations experienced the largest increase in patients seen by nurse practitioners. Health Aff (Millwood) 2013;32:1236-43.

13. Peabody JW, Luck J, Glassman P, Dresselhaus TR, Lee M. Comparison of vignettes, standardized patients, and chart abstraction: a prospective validation study of 3 methods for measuring quality. JAMA 2000;283:1715-22.

14. Caverly TJ, Fagerlin A, Zikmund-Fisher B, et al. Appropriate prescribing for patients with diabetes at high risk for hypoglycemia: national survey of Veterans Affairs health care professionals. JAMA Intern Med 2015;175:1994-6.

15. Epstein AM. Pay for performance at the tipping point. N Engl J Med 2007;356:515-7.

16. Rosenthal MB, Landon BE, Normand S-LT, Frank RG, Epstein AM. Pay for performance in 
commercial HMOs. N Engl J Med 2006;355: 1895-902.

17. Sussman JB, Kerr EA, Saini SD, et al. Rates of deintensification of blood pressure and glycemic medication treatment based on levels of control and life expectancy in older patients with diabetes mellitus. JAMA Intern Med 2015;175:1942-9.

18. Rodriguez-Gutierrez R, Lipska KJ, McCoy RG, Ospina NS, Ting HH, Montori VM; Hypoglycemia as a Quality Measure in Diabetes Study Group. Hypoglycemia as an indicator of good diabetes care. BMJ. 2016;352:i1084.

19. Adler KG. Holy MACRA! Will our future be better or worse? Fam Pract Manag 2016;23:5.

20. Levy AR, Tamblyn RM, McLeod PJ, Fitchett D, Abrahamowicz $M$. The effect of physicians' training on prescribing beta-blockers for secondary prevention of myocardial infarction in the elderly. Ann Epidemiol 2002;12:86-9.

21. Marcum ZA, Driessen J, Thorpe CT, Donohue JM, Gellad WF. Regional variation in use of a new class of antidiabetic medication among Medicare beneficiaries: the case of incretin mimetics. Ann Pharmacother 2015;49:285-92.

22. Wazana A. Physicians and the pharmaceutical industry: is a gift ever just a gift? JAMA 2000;283:373-80.

23. McCarthy M. Doctors who take company cash are more likely to prescribe brand name drugs, analysis finds. BMJ 2016;352:i1645.

24. Joyce GF, Carrera M, Goldman DP, Sood N. Physician prescribing behavior and its impact on patientlevel outcomes. Am J Manag Care 2011;17:e462-71.

25. Abdelhafiz AH, Rodriguez-Manas L, Morley JE, Sinclair AJ. Hypoglycemia in older people - a less well recognized risk factor for frailty. Aging Dis 2015;6:156-67.

26. Geller AI, Shehab N, Lovegrove MC, et al. National estimates of insulin-related hypoglycemia and errors leading to emergency department visits and hospitalizations. JAMA Intern Med 2014;174:678-86.

27. Lipska KJ, Krumholz H, Soones T, Lee SJ. Polypharmacy in the aging patient: a review of glycemic control in older adults with type 2 diabetes. JAMA 2016;315:1034-45.

28. Thorpe CT, Gellad WF, Good CB, et al. Tight glycemic control and use of hypoglycemic medi- cations in older veterans with type 2 diabetes and comorbid dementia. Diabetes Care 2015;38: 588-95.

\section{Appendix}

\section{Sample Vignette}

Mrs. Brown is $\mathbf{8 0}$ years old and has had type 2 diabetes for 15 years. Three months ago, Mrs. Brown was prescribed metformin $1000 \mathrm{mg}$ (BID), an ACE inhibitor, to control comorbid hypertension, and low-dose aspirin. Mrs. Brown currently has an $\mathbf{H b A}_{\mathbf{1 c}}$ of $7.5 \%$, a BP of $140 / 80 \mathrm{mmHg}$, and a BMI of 29. Her basic metabolic profile is normal and her GFR is $>60$. Mrs. Brown has coronary artery disease, for which she underwent a coronary artery bypass graft 5 years ago. Mrs. Brown reports intermittent pain in her feet, but she has difficulty localizing it. There is no history of depression. Mrs. Brown has some recent memory loss on formal testing. She lives independently but depends on her eldest daughter to keep her medical appointments and pay her bills. She stopped driving, in part because she occasionally got lost. Mrs. Brown is able to afford her medications.

1. Which antihyperglycemic treatment option are you most likely to recommend? Mark only 1 .

$\square$ Continue metformin (Glucophage) monotherapy

$\square$ Metformin (Glucophage) + sulfonylurea (glipizide, glyburide, glimepiride [Amaryl])

$\square$ Metformin (Glucophage) + thiazolidinedione (pioglitazone [Actos])

$\square$ Metformin (Glucophage) + DPP-4 inhibitor (sitagliptin [Januvia], saxagliptin [Onglyza])

$\square$ Metformin (Glucophage) + GLP-1 receptor agonist (exenatide, liraglutide)

$\square$ Metformin (Glucophage) + long-acting insulin (insulin glargine [Lantus], insulin detemir [Detemir, Levemir]) 